\title{
Study of Cardiovascular Changes in Adolescents with Simple Obesity
}

\author{
Heba H. Mohamed ${ }^{1}$, Somaya M. Abd El-Ghany², Sahar A. Khairy³, Eman A. Ahmed ${ }^{2}$, \\ Ahmed M. Al Emam \\ ${ }^{1}$ Department of Cardiology, National Heart Institute, Cairo, Egypt \\ ${ }^{2}$ Department of Pediatrics, Faculty of Medicine for Girls, Al-Azhar University, Cairo, Egypt \\ ${ }^{3}$ Department of Nutritional Requirements and Growth, National Nutrition Institute, Cairo, Egypt \\ Email: heba_pediatric@hotmail.com
}

How to cite this paper: Mohamed, H.H., Abd El-Ghany, S.M., Khairy, S.A., Ahmed, E.A. and Al Emam, A.M. (2021) Study of Cardiovascular Changes in Adolescents with Simple Obesity. Open Access Library Journal, 8: e7365.

https://doi.org/10.4236/oalib.1107365

Received: March 29, 2021

Accepted: May 23, 2021

Published: May 26, 2021

Copyright $\odot 2021$ by author(s) and Open Access Library Inc.

This work is licensed under the Creative Commons Attribution International License (CC BY 4.0).

http://creativecommons.org/licenses/by/4.0/

\section{Open Access}

\begin{abstract}
Obesity is a risk factor for cardiovascular morbidity and mortality that has deleterious effects on cardiovascular function. The aim of this work was to screen early cardiovascular abnormalities in obese asymptomatic adolescents using Conventional Echocardiography and Electrocardiogram. Fifty asymptomatic obese adolescents selected from National Heart Institute were compared to fifty non-obese normal controls with mean age of $(12.44 \pm 1.91)$ and $(11.99 \pm 1.89)$ years respectively. All studied adolescents were subjected to: careful history taking, complete clinical examination, laboratory investigation: fasting blood glucose, lipid profile, fasting insulin, insulin resistance, echocardiography and ECG. Results: It revealed statistical significant differences between obese and non-obese groups regarding left ventricle septal wall in diastole (LVSd), posterior wall thickness in diastole (LVPWd), relative wall thickness (RWT), LV end diastolic and systolic diameter (LVEDD and LVESD) and LV mass (P-value: 0.000). The left atrial dimensions (LA) were also significantly higher in the obese subjects than in the control group (P-value: 0.000). For the Doppler measurements, the early and late mitral valve velocity and the ratio between them (MVE velocity, MVA velocity and MV E/A) were significantly higher in obese than control subjects (P-value: 0.000). A strong positive correlation was noted between BMI and left atrial size (P-value: 0.003), left ventricular septum in diastole (LVSd) (P-value: 0.000), LVEDD (P-value: 0.005 ) and LVESD (P-value: 0.000$)$, posterior wall thickness in diastole (LVPWd) (P-value: 0.012), left ventricle septal wall in diastole (LVSd) (P-value: 0.000) and left ventricular mass (P-value: 0.010). Conclusion: This study demonstrated that asymptomatic obese adolescents had significant changes in left ventricular dimensions and early diastolic filling compared to non-obese subjects.
\end{abstract}




\section{Subject Areas}

Cardiology

\section{Keywords}

Obesity, Left Ventricular Function

\section{Introduction}

Obesity in adolescence has reached epidemic proportions around the world, with the prevalence of severe obesity increasing at least 4 -fold over the last 35 years. Most youths with obesity carry their excess adiposity into adulthood [1]. This represents a situation that demands urgent attention to avoid its potential morbidity and mortality [2].

Obesity is a risk factor for cardiovascular morbidity and mortality that has deleterious effects on cardiovascular function [3]. There have been some reports that obesity in children and adolescents causes echocardiographic as well as ECG abnormalities with an increased risk of adverse cardiovascular outcomes [4]. Subclinical changes in myocardial function and endothelial regulation, and tendency to hypertension have been reported among obese children and adolescents [5].

There is strong evidence that weight loss in overweight or obese individuals reduces the risk of diabetes and cardiovascular diseases [6].

\subsection{Aim of the Work}

To screen early cardiovascular abnormalities in obese asymptomatic adolescents using conventional echocardiography and electrocardiogram.

\subsection{Subjects and Methods}

The current study was a cross sectional comparative study that included 100 adolescents: 50 of them had simple obesity and were free of cardiac symptoms and the remaining 50 were apparently healthy non-obese adolescents. Cases were randomly selected from obesity clinic of National Nutrition Institute, during the period of March 2017 to March 2019. The eligibility criteria for participants of the obese subjects were the ones defined by WHO percentile Body Mass Index "BMI"/age for males and females [7]. Any participant having secondary obesity or a chronic illness involving the heart, or being taking medications associated with weight change was excluded from this study.

All studied adolescents were subjected to: complete medical history, thorough clinical examination to exclude secondary obesity \& chronic disease, anthropometric measurements (weight, height, waist circumference \& BMI), laboratory investigation (lipid profile, fasting blood glucose \& fasting insulin), echocardiographic measurements and electrocardiography. 


\subsection{Ethical Considerations}

Written informed consent from all participant families was taken prior to their enrolment into the study.

\section{Methodology}

- Anthropometric measures were measured according to standardized methods of WHO [7]. BMI was calculated as weight divided by the square of height $\left(\mathrm{kg} / \mathrm{m}^{2}\right)$ [8]. The WHO percentile body mass index "BMI"/age for males and females charts was used to determine the body status [7] (Table 1).

- Laboratory investigation. Participants were asked to fast the night before the blood was collected from them. Fasting blood glucose [9], fasting insulin [10] and lipid profile [11] were determined.

- Echocardiographic measurements. All measurements had been performed according to the recommendations of the American Society of Echocardiography (ASE) [12] including:

Standard resting transthoracic echocardiography (TTE): all patients had undergone TTE using General Electric VIVID 7, Echo ultrasonography machine 2008, and M4S transducer, with a frequency of $1.5-4.3 \mathrm{MHz}$ and $5 \mathrm{~S}$ with frequency $5 \mathrm{MHz}$.

The following criteria have been evaluated:

1) Left ventricular systolic function; left ventricular end diastolic (EDD), end systolic diameter (ESD) and ejection fraction (EF) had been obtained in the parasternal short axis-papillary level view using $M$ mode and in the leading edge methodology [12].

2) The relative wall thickness (RWT); has been calculated from the posterior wall thickness (PWT) and the EDD, as (2xPWT)/EDD. Above normal values indicate increased RWT according to Neadorf and his colleagues [13].

3) The LV mass had been calculated using the following equation:

$$
\mathrm{LV} \text { mass }=0.8\left[1.4 \times(\mathrm{PWT}+\mathrm{VST}+\mathrm{LVEDD})^{3}-(\mathrm{LVEDD})^{3}\right]+0.6 \text {. Above }
$$
normal value indicates LV hypertrophy [14].

4) LV mass index; had been calculated as the LV mass/body surface area $(\mathrm{BSA})$. BSA $=0.007184 \times(\text { weight in } \mathrm{Kg})^{0.425} \times(\text { Height in } \mathrm{M})^{0.725}$. Above normal value indicates LV hypertrophy [13].

5) Left ventricular diastolic function: Pulsed Doppler measurements had been obtained in the apical four chambers view. The Doppler beam had been aligned perpendicular to the plane of the mitral annulus and a $5 \mathrm{~mm}$-pulsed wave Doppler sample volume was placed between the tips of the mitral leaflets during

Table 1. BMI/age for males and females charts.

\begin{tabular}{cc}
\hline Normal Weight & $5^{\text {th }}<85^{\text {th }}$ percentile \\
Over-weight & $85^{\text {th }}<95^{\text {th }}$ percentile \\
Obese & $>95^{\text {th }}$ percentile \\
\hline
\end{tabular}


diastole. The following variables had been calculated: maximum velocity of early mitral filling (E), maximum velocity of late mitral filling (A), ratio of early to late velocity (E/A) [14].

6) Cardiac morphology: left atrial diameter, left ventricular end diastolic diameter (LVEDD), the relative wall thickness (RWT) and left ventricular mass (LV mass) [15].

7) Diastolic function had been calculated by measuring the following velocities:

o Early diastolic velocity $(E)$ : By measuring the peak velocity of early diastolic mitral inflow in all parts of mitral annulus (normal value is $\geq 0.04 \mathrm{~m} / \mathrm{sec}$, and if it is $\leq 0.04 \mathrm{~m} / \mathrm{sec}$, it indicated LV diastolic dysfunction).

o Late diastolic velocity $\left(A^{\prime}\right)$ : by measuring the peak velocity of late diastolic mitral inflow in all parts of mitral annulus.

o El A' ratio [16].

- Electrocardiography. Twelve-lead resting electrocardiogram (ECG) was conducted for all adolescents using Philips machine, model: CARDIOVIT-AT2, year of establishment. 1999 for assessment of ECG data including all waves, intervals, axis deviation and any arrythmias.

Statistical analysis. Statistics was performed through IBM PC, using Statistical Package for Special Science (SPSS) software computer program version 23. The tests used were.

1) Chi-square test andlor Fisher exact test when the expected count in any cell found less than 5 .

2) Independent $t$-test for parametric data while with nonparametric data were done by using Mann-Whitney test.

3) Linear regression analysis was used to assess the correlation between echo parameters with weight and BMI of the studied cases.

4) Confidence interval was set to $95 \%$ and the margin of error accepted was set to $5 \%$. So, the p-value was considered significant as the following.

$P$-value $>0.05:$ Non significant $(N S)$

$P$-value $<0.05$ : Significant $(S)$.

\section{Results}

Results for this work are presented in Tables 2-7.

\section{Discussion}

Obesity in children and adolescents is one of the most alarming public health issues facing the world. It has long-term adverse effects on morbidity and mortality [17]. Adolescence has been identified as a critical period for the development of persistent obesity on the basis of the strong evidence for tracking of adolescent adiposity into adulthood. Adolescent obesity is associated with all the long-term risks of adult obesity and carries additional risks for metabolic disorders associated with the earlier onset [18]. The current study provided evidence 
Table 2. Comparison between left side heart dimensions among both studied groups.

\begin{tabular}{|c|c|c|c|c|c|c|}
\hline \multirow{2}{*}{\multicolumn{2}{|c|}{ Echo measurements }} & \multirow{2}{*}{$\begin{array}{c}\text { Obese group } \\
\text { No. }=\mathbf{5 0}\end{array}$} & \multirow{2}{*}{$\begin{array}{c}\text { Control group } \\
\text { No. }=\mathbf{5 0}\end{array}$} & \multirow{2}{*}{ Test value } & \multirow{2}{*}{$P$-value } & \multirow{2}{*}{ Sig. } \\
\hline & & & & & & \\
\hline \multirow{2}{*}{ LVSd } & Mean \pm SD & $0.85 \pm 0.18$ & $0.60 \pm 0.06$ & \multirow{2}{*}{9.134} & \multirow{2}{*}{0.000} & \multirow{2}{*}{ HS } \\
\hline & Range & $0.6-1.2$ & $0.5-0.7$ & & & \\
\hline \multirow{2}{*}{ LVSs } & Mean \pm SD & $1.27 \pm 0.31$ & $0.80 \pm 0.16$ & \multirow{2}{*}{9.438} & \multirow{2}{*}{0.000} & \multirow{2}{*}{ HS } \\
\hline & Range & $0.7-1.9$ & $0.7-1.1$ & & & \\
\hline \multirow{2}{*}{ LVIDd } & Mean \pm SD & $4.49 \pm 0.49$ & $3.92 \pm 0.16$ & \multirow{2}{*}{7.926} & \multirow{2}{*}{0.000} & \multirow{2}{*}{ HS } \\
\hline & Range & $3.7-5.5$ & $3.8-4.2$ & & & \\
\hline \multirow{2}{*}{ LVIDs } & Mean \pm SD & $2.85 \pm 0.53$ & $2.38 \pm 0.08$ & \multirow{2}{*}{6.199} & \multirow{2}{*}{0.000} & \multirow{2}{*}{ HS } \\
\hline & Range & $2-4$ & $2.3-2.5$ & & & \\
\hline \multirow{2}{*}{ LV PWd } & Mean \pm SD & $0.85 \pm 0.24$ & $0.48 \pm 0.12$ & \multirow{2}{*}{9.815} & \multirow{2}{*}{0.000} & \multirow{2}{*}{ HS } \\
\hline & Range & $0.5-1.7$ & $0.4-0.7$ & & & \\
\hline \multirow{2}{*}{ LA size } & Mean \pm SD & $3.08 \pm 0.54$ & $2.18 \pm 0.24$ & \multirow{2}{*}{10.753} & \multirow{2}{*}{0.000} & \multirow{2}{*}{ HS } \\
\hline & Range & $2.2-3.8$ & $2-2.6$ & & & \\
\hline
\end{tabular}

There was statistically significant increase in left ventricular dimensions and left atrium size among obese group compared to control group.

Table 3. Comparison between systolic function and LV mass among studied group.

\begin{tabular}{ccccccc}
\hline \multicolumn{2}{c}{ ECHO finding } & $\begin{array}{c}\text { Obese group } \\
\text { No. }=\mathbf{5 0}\end{array}$ & $\begin{array}{c}\text { Control } \\
\text { group } \\
\text { No. }=\mathbf{5 0}\end{array}$ & $\begin{array}{c}\text { Test } \\
\text { value }\end{array}$ & P-value & Sig. \\
\hline $\begin{array}{c}\text { LV systolic } \\
\text { function (EF\%) }\end{array}$ & Mean \pm SD & $69.94 \pm 6.84$ & $69.92 \pm 3.38$ & $0.019 \bullet$ & 0.985 & NS \\
Range & $55-80$ & $65-77$ & & & \\
RWT & Mean \pm SD & $0.37 \pm 0.10$ & $0.28 \pm 0.08$ & $4.970 \bullet$ & $\mathbf{0 . 0 0 0}$ & HS \\
& Range & $0.23-0.73$ & $0.21-0.39$ & & & \\
LV mass & Mean \pm SD & $124.52 \pm 41.80$ & $54.20 \pm 14.42$ & $11.244 \bullet$ & 0.000 & HS \\
& Range & $62-194$ & $41-78$ & & & \\
LV mass index & Mean \pm SD & $70.70 \pm 22.63$ & $44.00 \pm 9.73$ & $7.664 \bullet$ & $\mathbf{0 . 0 0 0}$ & HS \\
& Range & $30-109$ & $36-62$ & & & \\
\hline
\end{tabular}

There was statistically significant increase in RWT, LV mass and LV mass index among obese group compared to control group.

Table 4. Comparison between LV morphology among studied group.

\begin{tabular}{ccccccc}
\hline \multirow{2}{*}{ ECHO finding } & $\begin{array}{c}\text { Obese } \\
\text { group } \\
\text { No. }=\mathbf{5 0}\end{array}$ & $\begin{array}{c}\text { Control group } \\
\text { No. }=\mathbf{5 0}\end{array}$ & $\begin{array}{c}\text { Test } \\
\text { value }\end{array}$ & P-value & Sig. \\
\hline \multirow{2}{*}{ LV morphology } & $\begin{array}{c}37 \\
(74.0 \%)\end{array}$ & $50(100.0 \%)$ & & & \\
\hline & $\begin{array}{c}\text { Concentric } \\
\text { remodeling } \\
\text { Concentric } \\
\text { hypertrophy }\end{array}$ & $\begin{array}{c}(10.0 \%) \\
(16.0 \%)\end{array}$ & $0(0.0 \%)$ & $14.943^{*}$ & $\mathbf{0 . 0 1 0}$ & HS \\
\hline
\end{tabular}

Obese adolescents showed significant LV concentric remodeling and hypertrophy when compared to controls. 
Table 5. Comparison between diastolic function of left ventricle among both studied groups.

\begin{tabular}{|c|c|c|c|c|c|c|}
\hline \multirow{2}{*}{\multicolumn{2}{|c|}{ Echo measurements }} & Obese group & Control group & \multirow{2}{*}{$\begin{array}{c}\text { Test } \\
\text { value }\end{array}$} & \multirow{2}{*}{$P$-value } & \multirow{2}{*}{ Sig. } \\
\hline & & No. $=50$ & No. $=50$ & & & \\
\hline \multirow{2}{*}{ MV E vel } & Mean \pm SD & $1.07 \pm 0.18$ & $0.91 \pm 0.12$ & \multirow{2}{*}{5.361} & \multirow{2}{*}{0.000} & \multirow{2}{*}{ HS } \\
\hline & Range & $0.74-1.47$ & $0.75-1.1$ & & & \\
\hline \multirow{2}{*}{ MV A vel } & Mean \pm SD & $0.63 \pm 0.11$ & $0.54 \pm 0.06$ & \multirow{2}{*}{5.252} & \multirow{2}{*}{0.000} & \multirow{2}{*}{ HS } \\
\hline & Range & $0.45-0.88$ & $0.45-0.6$ & & & \\
\hline \multirow{2}{*}{ E/A ratio } & Mean \pm SD & $1.69 \pm 0.31$ & $1.44 \pm 0.16$ & \multirow{2}{*}{$4.953 \bullet$} & \multirow{2}{*}{0.000} & \multirow{2}{*}{ HS } \\
\hline & Range & $1.2-2.2$ & $1.2-1.7$ & & & \\
\hline
\end{tabular}

There was significant increase in the E/A ratio among obese group when compared to control group. Indicating decrease diastolic function in obese group than control.

Table 6. Comparison between ECG finding among studied groups.

\begin{tabular}{|c|c|c|c|c|c|}
\hline \multirow{2}{*}{\multicolumn{2}{|c|}{ ECG }} & Obese cases & Normal cases & \multirow{2}{*}{ P-value } & \multirow{2}{*}{ Sig. } \\
\hline & & No. $=50$ & No. $=50$ & & \\
\hline \multirow{2}{*}{$\begin{array}{l}\text { Heart rate } \\
(\mathrm{BPM})\end{array}$} & Mean \pm SD & $78.64 \pm 10.59$ & $77.10 \pm 11.93$ & \multirow{2}{*}{0.496} & \multirow{2}{*}{ NS } \\
\hline & Range & $64-98$ & $56-98$ & & \\
\hline \multirow{2}{*}{$\begin{array}{l}\text { PR interval } \\
\quad(\mathrm{ms})\end{array}$} & Mean \pm SD & $113.60 \pm 14.81$ & $118.00 \pm 14.57$ & \multirow{2}{*}{0.137} & \multirow{2}{*}{ NS } \\
\hline & Range & $80-120$ & $80-150$ & & \\
\hline \multirow{2}{*}{$\begin{array}{l}\text { QRS interval } \\
\quad(\mathrm{ms})\end{array}$} & Mean \pm SD & $118.80 \pm 14.80$ & $118.20 \pm 16.25$ & \multirow{2}{*}{0.847} & \multirow{2}{*}{ NS } \\
\hline & Range & $80-140$ & $80-150$ & & \\
\hline \multirow{2}{*}{$\begin{array}{l}\text { ST segment } \\
\quad(\mathrm{ms})\end{array}$} & Mean \pm SD & $202.80 \pm 40.66$ & $199.20 \pm 41.25$ & \multirow{2}{*}{0.661} & \multirow{2}{*}{ NS } \\
\hline & Range & $150-280$ & $120-280$ & & \\
\hline \multirow{2}{*}{$\begin{array}{l}\text { Corrected QT interval } \\
(\mathrm{ms})\end{array}$} & Mean \pm SD & $321.60 \pm 36.50$ & $317.40 \pm 33.86$ & \multirow{2}{*}{0.552} & \multirow{2}{*}{ NS } \\
\hline & Range & $270-400$ & $270-400$ & & \\
\hline \multirow{2}{*}{ Lt axis deviation } & No & $40(80.0 \%)$ & $50(100.0 \%)$ & \multirow{2}{*}{0.001} & \multirow{2}{*}{ HS } \\
\hline & Yes & $10(20.0 \%)$ & $0(0.0 \%)$ & & \\
\hline
\end{tabular}

There was no significant difference between the two studied group in ECG findings except for left axis deviation.

that asymptomatic obese children already exhibit abnormalities in left ventricular structure and function (consisting of increase left ventricular wall dimensions, mass, and alteration in diastolic function). This is in agreement with Putte-Katier et al. (2008) [19] and Kibar et al. (2012) [20]. Our results had shown that obesity affected the cardiac morphology and the diastolic function of left ventricle more than the systolic function.

Regarding the cardiac morphology, our results had shown that there was high significant increase in left atrium diameter and left ventricular mass (LVM) in obese compared to non-obese subjects. The Bogalusa Heart Study showed a strong association between LVM in childhood and degree of obesity [21] in agreement with our results. Okpara et al. (2010) [2] suggested that left atrium enlargement is an independent risk factor for adverse cardiovascular outcome. 
Table 7. Correlation between echocardiographic parameters and BMI.

\begin{tabular}{ccc}
\hline & \multicolumn{2}{c}{ BMI } \\
\cline { 2 - 3 } & r & P-value \\
\hline LA size & 0.413 & $0.003^{* *}$ \\
RWT & -0.212 & 0.140 \\
LV mass & 0.361 & $0.010^{* *}$ \\
LVESD & 0.484 & $0.000^{* *}$ \\
LVEDD & 0.395 & $0.005^{* *}$ \\
LVPWd & 0.354 & $0.012^{*}$ \\
LVSd & 0.485 & $0.000^{* *}$ \\
LVSs & -0.146 & 0.311 \\
MV E vel & -0.062 & 0.666 \\
MV A vel & -0.018 & 0.901 \\
\hline
\end{tabular}

There was significant positive correlation between LA size, LV mass, LVESD, LVEDD, LVPWd, LVSd and BMI.

They also demonstrated that obesity was associated with increased left ventricle wall thickness (LVSD and PWTD), increased left ventricle internal diameter (LVID), increased LV mass and hypertrophy (LVM, LVH). These data are matched with ours. Deng et al. (2010) [22] reported that LVM and LV mass index were significantly higher in obese than non-obese group. We found that $10 \%$ had concentric remodeling and 16\% had concentric hypertrophy versus $100 \%$ normal cardiac morphology in control group in agreement with our results. Peterson et al. (2004) [23], reported that concentric LV hypertrophy was a predominant finding in obese subjects. These results suggest that left ventricular hypertrophy $(\mathrm{LVH})$ is one of the cardiac complications of obesity and echo cardio-graphically determined LVH is a powerful independent predictor cardiovascular morbidity and mortality [24].

Regarding Diastolic Function, conventional Echo Doppler can detect the diastolic dysfunction subclinical left ventricular dysfunction in several disorders with normal standard parameters of global left ventricular systolic function [25]. The wide spread use of pulsed Doppler Echocardiography has facilitated the noninvasive evaluation of abnormalities in the hemodynamic events between left atrium (LA) and left ventricle (LV) by using transmitral flow velocity pattern [26]. In the present study, Conventional Doppler measurements indices of septal mitral annulus showed statistical significant difference in MVE, MVA and $\mathrm{MVE} / \mathrm{A}$ ratio between the obese and non-obese groups. Supporting these findings, Wouter et al. (2018) [27] found that, in obese adolescents, mitral A-wave velocity, E-wave velocity were significantly elevated, as opposed to lean controls.

Regarding the systolic function, we observed no difference in left ventricular ejection fraction between obese and control groups, which was in agreement with the results of the sudy of Mehta et al. (2004) [28].

Regarding the correlation between cardiac findings with obesity \& obesity 
related complication in the present study, we found significant positive correlation between BMI and each of the following cardiac dimensions: LAD, LVIDs, LVIDd, LVPWd, LVSd and LV mass.

\section{Conclusions and Recommendations}

In conclusion, present study demonstrated that:

- Left sided cardiac dimensions were significantly increased in studied obese adolescents than controls.

- Both MVE and MVA as well as E/A ratio were significantly higher in obese adolescents compared to controls indicating LV diastolic dysfunction.

- Concentric LV hypertrophy was significantly higher in obese adolescents than controls.

- A significant positive correlation was found between LV dimensions and BMI in obese adolescents.

The onset of obesity associated cardiac disease is asymptomatic so, periodic cardiac monitoring is recommended for its detection \& management.

\section{Conflicts of Interest}

The authors declare no conflicts of interest regarding the publication of this paper.

\section{References}

[1] Cardel, M.I., Atkinson, M.A., Taveras, E.M., Holm, J.-C. and Kelly, A.S. (2020) Obesity Treatment Among Adolescents: A Review of Current Evidence and Future Directions. JAMA Pediatrics, 174, 609-617.

https://doi.org/10.1001/jamapediatrics.2020.0085

[2] Okpara, I.C., Adediran, O.S., Odia, O.J. and Uchenna, D.I. (2010) The Relationship Between Measures of Obesity and Echocardiographic Determinants of Left Ventricular Hypertrophy in Nigerian Adults. The Internet Journal of Cardiology, 9, 1-9.

[3] Saltijeral, A., Perez de Isla, L. and Zamorano, J. (2011) Obesity Cardiomyopathy in Children. Journal of the ESC Council for Cardiology Practice, 10, 157.

[4] O’Neil, B.J., Hoekstra, J., Pride, Y.B., Lefebvre, C., Diercks, D., Frank Peacock, W., et al. (2010) Incremental Benefit of 80-Lead Electrocardiogram Body Surface Mapping over the 12-Lead Electrocardiogram in the Detection of Acute Coronary Syndromes in Patients without ST-Elevation Myocardial Infarction: Results from the Optimal Cardiovascular Diagnostic Evaluation Enabling Faster Treatment of Myocardial Infarction (OCCULT MI) Trial. Academic Emergency Medicine, 17, 932-939. https://doi.org/10.1111/j.1553-2712.2010.00848.x

[5] Santoro, N., del Giudice, E.M., Grandone, A., Marzuillo, P., Cozzolino, D., Di Salvo, G., et al. (2008) Y2 Receptor Gene Variants Reduce the Risk of Hypertension in Obese Children and Adolescents. Journal of Hypertension, 8, 1590-1594. https://doi.org/10.1097/HJH.0b013e32830413ed

[6] National Institute for Health and Clinical Excellence (2006) Clinical Guideline 43; Obesity: The Prevention, Identification, Assessment and Management of Overweight and Obesity in Adults and Children. National Institute for Health and Clinical Excellence, London. 
[7] World Health Organization (1995) Physical Status. The Use and Interpretation of Anthropometr. Report of a WHO Expert Committee. Technical Report Series No. 854, World Health Organization, Geneva, 268-329.

[8] Kuczmarski, R.J., Ogden, C.L., Guo, S.S., Grummer-Strawn, L.M., Flegal, K.M., Mei, Z., Wei, R., Curtin, L.R., Roche, A.F. and Johnson, C.L. (2002) Growth Charts for the United States: Methods and Development. United States Vital Statistics, No. 246, 1-190.

[9] Werner, W., Rey, H.G. and Wielinger, H. (1970) Über die Eigenschaften eines neuen Chromogens für die Blutzuckerbestimmung nach der GOD/POD-Methode: On the Properties of a New Chromogen for the Determination of Glucose in Blood According to the GOD/POD-Method. Fresenius Zeitschrift Für Analytische Chemie, 52, 224-228. https://doi.org/10.1007/BF00546391

[10] Boehm, T.M. and Lebovitz, H.E. (1979) Statistical Analysis of Glucose and Insulin Responses to Intravenous Tolbutamide: Evaluation of Hypoglycemic and Hyperinsulinemic States. Diabetes Care, 2, 479-490. https://doi.org/10.2337/diacare.2.6.479

[11] Trinder, P. and Webster, D. (1984) Determination of HDL Cholesterol Using 2, 4, 6-Tribromo-3-Hydroxybenzoic Acid with a Commercial CHOD-PAP Reagent. Annals of Clinical Biochemistry, 21, 430-433. https://doi.org/10.1177\%2F000456328402100516

[12] Lang, R.M., Bierig, M., Devereux, R.B., Flachskampf, F.A., Foster, E., Pellikka, P.A., et al. (2005) Recommendations for Chamber Quantification. Journal of the American Society of Echocardiography, 12, 1440-1463. https://doi.org/10.1016/j.echo.2005.10.005

[13] Niadorf, S.M., Picard, M.H., Triulzi, M.O., Thomas, J.D., Newell, J., Etta King, M., et al. (1992) New Perspectives in the Assessment of Cardiac Chamber Dimensions during Development and Adulthood. Journal of the American College of Cardiolo$g y$, 19, 983-988. https://doi.org/10.1016/0735-1097(92)90282-R

[14] Nishimura, R.A. and Tajik, A.J. (1997) Evaluation of Diastolic Filling of Left Ventricle in Health and Disease: Doppler Echocardiography Is the Clinician's Rosetta Stone. Journal of the American College of Cardiology, 30, 8-18. https://doi.org/10.1016/S0735-1097(97)00144-7

[15] American Society of Echocardiography Committee on Standards and Subcommittee on Quantitation of Two-Dimensional Echocardiograms (1989) Recommendations for Quantitation of the Left Ventricle by Two-Dimensional Echocardiography. Journal of the American Society of Echocardiography, 2, 358-367. https://doi.org/10.1016/S0894-7317(89)80014-8

[16] Sun, J.P. (2007) Future Applications of Speckle Tracking Echocardiography. In: Marwick, T.H., Yu, C.M. and Sun, J.P., Eds., Myocardial Imaging. Tissue Doppler and Speckle Tracking, Blackwell Publishing Ltd., Oxford, 301-314. https://doi.org/10.1002/9780470692448.ch26

[17] Lateva, M., Bliznakova, D., Galcheva, S., Bocheva, Y., Neshkinska, M., Mladenov, V., Halvadzhiyan, I., Yordanova, G., Boyadzhiev, V., Yotov, Y. and Conev, N. (2017) Childhood Obesity, Renal Injury and Future Disease Risk. Scripta Scientifica Medica, 49, 38-46. https://doi.org/10.14748/ssm.v49i1.2050

[18] Wardle, J., Brodersen, N.H., Cole, T.J., Jarvis, M.J. and Boniface, D.R. (2006) Development of Adiposity in Adolescence: Five Year Longitudinal Study of an Ethnically and Socioeconomically Diverse Sample of Young People in Britain. BMJ, 332, 1130-1135. https://doi.org/10.1136/bmj.38807.594792.AE

[19] Van Putte-Katier, N., Rooman, R.P., Haas, L., Verhulst, S.L., Desager, K.N., Ramet, 
J. and Suys, B.E. (2008) Early Cardiac Abnormalities in Obese Children: Importance of Obesity per se versus Associated Cardiovascular Risk Factors. Pediatric Research, 64, 205-209. https://doi.org/10.1203/PDR.0b013e318176182b

[20] Kibar, A.E., Pac, F.A., Oflaz, M.B., Balli, S. and Ece, I. (2012) Echocardiographic Evaluation of Left Ventricular Function in Normotensive Obese Children: A Comparative Analysis According to Body Mass index. Archives of the Turkish Society of Cardiology, 40, 337-346. https://doi.org/10.5543/tkda.2012.49344

[21] Li, X., Li, S., Ulusoy, E., Chen, W., Srinivasan, S.R. and Berenson, G.S. (2004) Childhood Adiposity as a Predictor of Cardiac Mass in Adulthood: The Bogalusa Heart Study. Circulation, 110, 3488-3492. https://doi.org/10.1161/01.CIR.0000149713.48317.27

[22] Deng, Y., Alharthi, M.S., Thota, V.R., Yin, L., Li, C. and Emani, U.R., Chandrasekaran, K., Khandheria, B. and Mookadam, F. (2010) Evaluation of Left Ventricular Rotation in Obese Subjects by Velocity Vector Imaging. European Journal of Echocardiography, 11, 424-428. https://doi.org/10.1093/ejechocard/jep230

[23] Peterson, L.R., Herrero, P., Schechtman, K.B., Racette, S.B., Waggoner, A.D., Kisrieva-Ware, Z., Dence, C., Klein, S., Marsala, J., Meyer, T. and Gropler, R.J. (2004) Effect of Obesity and Insulin Resistance on Myocardial Substrate Metabolism and Efficiency in Young Women. Circulation, 109, 2191-2196. https://doi.org/10.1161/01.CIR.0000127959.28627.F8

[24] Levy, D., Garrison, R.J., Savage, D.D., Kannel, W.B. and Castelli, W.P. (1990) Prognostic Implications of Echocardiographically Determined Left Ventricular Mass in the Framingham Heart Study. New England Journal of Medicine, 322, 1561-1566. https://doi.org/10.1056/NEJM1990053132222203

[25] Alpert, M.A. (2001) Obesity Cardiomyopathy: Pathophysiology and Evolution of the Clinical Syndrome. American Journal of the Medical Sciences, 321, 225-236. https://doi.org/10.1097/00000441-200104000-00003

[26] Shalby, M. and Khalil, A. (2011) Cardiac Function in Obese People with Metabolic Syndrome. Kasr El-Aini Medical Journal, 17, 67-82.

[27] Franssen, W.M.A., Beyens, M., Al Hatawe, T. and Frederix, I. (2018) Cardiac Function in Adolescents with Obesity: Cardiometabolic Risk Factors and Impact on Physical Fitness. International Journal of Obesity, 43, 1400-1410. https://doi.org/10.1038/s41366-018-0292-x

[28] Mehta, S.K., Holliday, C., Hayduk, L., Wiersma, L., Richards, N. and Younosazi, A. (2004) Comparison of Myocardial Function in Children with Body Mass Indexes $\geq 25$ versus Those $<25 \mathrm{~kg} / \mathrm{m}^{2}$. American Journal of Cardiology, 93, 1567-1569. https://doi.org/10.1016/j.amjcard.2004.03.016 